\title{
Prognostic value of platelet indices after acute myocardial infarction treated with primary percutaneous coronary intervention
}

\author{
Tomasz Rechciński, Aleksandra Jasińska, Jakub Foryś, Maria Krzemińska-Pakuła, \\ Karina Wierzbowska-Drabik, Michał Plewka, Jan Zbigniew Peruga, \\ Jarosław Damian Kasprzak \\ Medical University of Lodz, Lodz, Poland
}

\begin{abstract}
Background: Mean platelet volume (MPV) is a strong predictor of impaired angiographic reperfusion and 6-month mortality in ST-elevation myocardial infarction (MI) treated with primary percutaneous coronary intervention (PCI). No data is available for other platelet volume indices: platelet distribution width (PDW) and platelet large cell ratio (P-LCR). The aim was to assess the impact of 3 platelet volume indices on long-term prognosis in patients treated with primary PCI in acute MI.
\end{abstract}

Methods: This prospective study enrolled 538 patients who underwent primary PCI in acute MI. Admission blood samples were measured for MPV, PDW, and P-LCR. The patients were followed-up a mean period of $26 \pm 11$ months with regard to cardiac death, non-fatal reinfarction, re-PCI or coronary artery bypass grafting.

Results: Kaplan-Meier survival analysis showed a significantly higher 26-month mortality rate in patients with high $M P V(\geq 11.7 \mathrm{fL})$ than in those with low $M P V(<11.7 \mathrm{fL})(14.6 \%$ vs. $5.5 \%, p=0.0008)$. Similar findings were related to high $P-L C R(\geq 38.1 \%)$ vs. low P-LCR $(<38.1 \%)$ - mortality $13.8 \%$ vs. $5.8 \%, p=0.0025$. Higher $P D W$ values $(\geq 16 \mathrm{fL})$ correlated with higher mortality rate as compared to $P D W<16 \mathrm{fL}(17.4 \%$ vs. $6.3 \%, p=0.0012)$. $P D W$ was found to be an independent prognostic factor for cardiac mortality and composite endpoint. Conclusions: Mean platelet volume, platelet distribution width and platelet large cell ratio measured on admission are strong, independent prognostic factors in PCI-treated acute MI. (Cardiol J 2013; 20, 5: 491-498)

Key words: platelets, prognosis, myocardial infarction

\section{Introduction}

Platelet activation plays a pivotal role for the initiation of acute coronary syndromes. Platelet size has been shown to correlate with their function. Large platelets are considered metabolically and enzymatically more reactive than smaller ones [1]. Increased mean platelet volume (MPV) is associated with extent of slow coronary flow [2]. MPV has been reported as increased in unstable angina pectoris and myocardial infarction (MI) [3]. Higher MPV after acute ischemic cerebrovascular

Address for correspondence: Tomasz Rechciński, MD, PhD, Medical University of Lodz, ul. Kniaziewicza 1/5, 91-347 Łódź, Poland, tel/fax: +48 422516112 /+48 4225160 15, e-mail: tomasz.rechcinski@umed.lodz.pl 
events is associated with worse outcome, as well as with higher risk of recurrent stroke [4, 5]. It has also been recognized as an independent risk factor for MI, but not for coronary artery disease prevalence [6, 7]. Measured at 6 months after acute MI, MPV has been shown to predict recurrent MI and death in 2-year follow up [8]. In ST-segment elevation MI treated with percutaneous coronary intervention (PCI), MPV has been observed to be a strong, independent factor of impaired angiographic reperfusion and 6-month mortality [9]. Platelet size has also been suggested to be correlated with the development of restenosis after successful coronary angioplasty [10].

Currently, automated cell counters enable routine availability of extended panel of platelet volume indices (PVI) beyond MPV, e.g. platelet distribution width (PDW) and platelet large cell ratio (P-LCR); there is, however, limited information on their clinical importance. The P-LCR indicates the percentage of large platelets with a volume $>12 \mathrm{fL}$. The share of platelets $>12 \mathrm{fL}$ in the total platelet number is presented as percentage and the normal range is $15-35 \%$. An increase in P-LCR may indicate the presence platelet aggregates, microerythrocytes and giant platelets.

The PDW is calculated as the platelet distribution width measured at $20 \%$ relative height of the total height of the curve depicting the distribution of them. An increased PDW is an indication for the anisocytosis of platelets. The normal range for PDW is 9 to $14 \mathrm{fL}$.

Thus, we designed the study to assess the impact of PVI, measured on admission, on long-term prognosis in patients after MI treated with primary percutaneous intervention.

\section{Methods}

\section{Study population}

The study group consisted of 538 consecutive patients with acute MI hospitalized in our department. The diagnosis of acute ST-elevation MI was established according to the ESC/ACC consensus [11]. Mean prehospital delay was $192 \pm 106$ (range 20-900) min. Blood samples were drawn on admission, before revascularization procedure. Coronary angiography and subsequent angioplasty were performed according to the standard femoral technique with mean door-to-needle time of $40 \mathrm{~min}$. $300 \mathrm{mg}$ of aspirin was administered before blood sampling, and continued thereafter at the daily dose of $75 \mathrm{mg}$. A loading dose of $300 \mathrm{mg}$ clopidogrel was given pre-procedurally and continued for 6 weeks
Table 1. The characteristics of study group.

\begin{tabular}{lc}
\hline Age [years] & $58 \pm 10$ \\
Male & $369(68.6 \%)$ \\
Diabetes & $61(11.3 \%)$ \\
Hypertension & $175(32.5 \%)$ \\
Smoking & $155(28.8 \%)$ \\
Previous MI & $57(15.9 \%)$ \\
Total cholesterol [mg/dL] & $210 \pm 48$ \\
LDL [mg/dL] & $135 \pm 43$ \\
HDL $[\mathrm{mg} / \mathrm{dL}]$ & $41 \pm 11$ \\
Triglycerides $[\mathrm{mg} / \mathrm{dL}]$ & $162 \pm 105$ \\
Hemoglobin $[\mathrm{g} / \mathrm{dL}]$ & $13.6 \pm 1.7$ \\
WBC [n $\left.\times 10^{3} / \mathrm{mm}^{3}\right]$ & $9.9 \pm 3.2$ \\
Platelet count $\left[\mathrm{n} \times 10^{3} / \mathrm{mm}^{3}\right]$ & $225 \pm 69$ \\
Mean platelet volume $[\mathrm{fL}]$ & $10.8 \pm 1.2$ \\
Platelet distribution width [fL] & $13.4 \pm 2.5$ \\
Platelet large cell ratio [\%] & $33.2 \pm 15.7$ \\
\hline
\end{tabular}

$\mathrm{MI}$ - myocardial infarction; LDL — low density lipoprotein; HDL — high density lipoprotein; WBC — white blood count

at the dose of $75 \mathrm{mg}$. The glycoprotein IIb/IIIa inhibitor - abciximab - was administered during the revascularization procedure at the operator's discretion in $62 \%(334 / 538)$ of cases, according to the patient's high risk. Baseline demographic and clinical data are shown in Table 1.

The study protocol was approved by the local ethics committee. The study complies with the Declaration of Helsinki. Informed consent has been obtained from all subjects.

\section{Follow up}

The patients were followed up for a mean time of $790 \pm 335$ days. The following clinical events were defined as endpoints: cardiac death (no non-cardiac death occurred), non-fatal re-infarction and repeat revascularization either percutaneous (PCI) or surgical (CABG, coronary artery bypass grafting). A combined endpoint (Composite), defined as occurrence of any endpoint: cardiac death or reinfarction or repeat revascularization, was also analyzed. Long-term follow-up data were obtained from all patients using available medical records and by telephone or personal contact.

\section{Laboratory methods}

Blood samples were drawn into standardized test tubes containing dipotassium edetic acid (EDTA). All samples were analyzed on Sysmex K-4500 automated cell counter (Sysmex Corporation Japan, Koebe, Japan), with time to result approximately $1 \mathrm{~min}$. Three platelet volume in- 
Table 2. Correlation between platelet volume indices and platelet count.

\begin{tabular}{lccc}
\hline & $\begin{array}{c}\text { Arithmetic } \\
\text { mean }\end{array}$ & $\begin{array}{c}\text { Spearman's rank } \\
\text { correlation coefficient } \rho\end{array}$ & $\begin{array}{c}\text { Statistical } \\
\text { significance } \mathbf{p}\end{array}$ \\
\hline Mean platelet volume [fL] & $10.8 \pm 1.2$ & -0.418 & $<0.001$ \\
Platelet distribution width [fL] & $13.4 \pm 6.3$ & -0.441 & $<0.001$ \\
Platelet large cell ratio [\%] & $33 \pm 16$ & -0.410 & $<0.001$ \\
\hline
\end{tabular}

Table 3. Relationship of platelet volume indices with age, biochemical and haematological parameters according to Spearman's rank correlation.

\begin{tabular}{lccc}
\hline & $\begin{array}{c}\text { Mean platelet } \\
\text { volume: } \mathbf{p}\end{array}$ & $\begin{array}{c}\text { Platelet distribution } \\
\text { width: } \mathbf{p}\end{array}$ & $\begin{array}{c}\text { Platelet large } \\
\text { cell ratio: } \mathbf{p}\end{array}$ \\
\hline Age & 0.603 (NS) & 0.221 (NS) & 0.367 (NS) \\
Total cholesterol & 0.211 (NS) & 0.575 (NS) & 0.815 (NS) \\
Low density lipoprotein & 0.090 (NS) & 0.079 (NS) & 0.445 (NS) \\
High density lipoprotein & 0.726 (NS) & 0.275 (NS) & 0.847 (NS) \\
Triglycerides & 0.830 (NS) & 0.637 (NS) & 0.909 (NS) \\
Haemoglobin & 0.432 (NS) & 0.067 (NS) & 0.637 (NS) \\
Red blood count & 0.757 (NS) & 0.069 (NS) & 0.715 (NS) \\
White blood count & 0.274 (NS) & 0.171 (NS) & 0.284 (NS) \\
Efficacy of reperfusion & 0.790 (NS) & 0.983 (NS) & 0.985 (NS) \\
\hline
\end{tabular}

NS — non-significant; efficacy of reperfusion was measured according to TIMI scale

dices: MPV, PDW and P-LCR, as well as platelet count were assessed. PDW and P-LCR data were obtained for 512 patients only. PDW was measured between $20^{\text {th }}$ and $80^{\text {th }}$ percentile of platelet histogram. P-LCR was defined by the cell counter manufacturer as the percentage of platelets larger than the constant cut-off of $12 \mathrm{fL}$.

\section{Statistical analysis}

Continuous variables are expressed as mean $\pm \mathrm{SD}$, whereas categorical variables are presented as absolute values and percentages. Patients were divided into groups based on MPV, PDW and P-LCR values. The cut-off values were determined by ROC analysis. Group differences of categorical variables were analyzed by a $\chi^{2}$ test with Yates correction for continuity while group differences of continuous variables were evaluated by ANOVA. Correlation between PVI and platelet count was calculated with Spearman's rank correlation coefficient. Survival rates were calculated by Kaplan-Meier curve analysis, with the differences in survival assessed using the log-rank test. The impact of abciximab administration was analyzed with Cox proportional-hazards regression. Multivariate analysis was performed with logistic regression, stepwise method. Differences were considered significant at the value of $\mathrm{p}<0.05$ (2-tailed). MedCalc version 7.3.0.1 (Belgium, Frank Schoonjans) statistical software was used to perform all statistical calculations.

\section{Results}

\section{The clinical events during follow-up}

There were 91 clinical events during follow-up (more than one event could be recoreded in individual patient), with event-free course in $452 / 538$ (84\%) patients. Mortality rate was $7.6 \%$ (41/538). $21 / 538(3.9 \%)$ patients had the recurrence of infarction, $5.3 \%$ underwent repeat revascularization with PCI (21/538) or CABG (8/538). The composite endpoint thus occurred in 16\% (86/538) of patients.

\section{Predictive values of platelet volume indices}

There was a negative correlation between the analyzed platelet volume indices and platelet count $-\operatorname{MPV}(\rho=-0.418 ; \mathrm{p}<001)$, PDW $(\rho=-0.441$, $\mathrm{p}<0.01)$, and P-LCR $(\rho=-0.410, \mathrm{p}<0.001)$ (Table 2), whereas there was no relationship with other clinical and laboratory data (Table 3).

As opposed to platelet count, all 3 PVI were highly predictive for cardiac mortality and composite clinical endpoint.

Receiver operating characteristics (ROC) were used to identify cut-off values for prediction 
of the occurrence of endpoints. The best cut-off values for prediction of the composite endpoint were $11.7 \mathrm{fL}$ for MPV, $16 \mathrm{fL}$ for PDW and $38.1 \%$ for P-LCR. The area under the ROC curve for MPV was 0.61 (95\% CI $0.57-0.65)$. The value of 11.7 had a positive predictive value (PPV) of $27.7 \%$ and negative predictive value (NPV) of $87.4 \%$. The area under the PDW ROC curve was also 0.61 (95\% CI $0.57-0.65)$, with PPV of the value $16 \mathrm{fL}$ as low as $36.4 \%$ but NPV of $87.2 \%$. The area under the ROC curve for P-LCR was 0.63 (95\% CI 0.58-0.67). The PPV was $27.1 \%$ while the NPV was $88 \%$. High MPV, defined as $\geq 11.7 \mathrm{fL}$, was observed in $22.9 \%$ (123/538) of patients, high PDW determined as $\geq 16 \mathrm{fL}$ was present in $13.5 \%$ (69/512), whereas high P-LCR $(\geq 38.1 \%)$ in $25.2 \%$ (129/512) of patients.

For cardiac mortality, the best cut-off value for MPV was $10.9 \mathrm{fL}$, with the area under ROC curve 0.65 (95\% CI $0.61-0.69)$, PPV of only $11.9 \%$, but NPV of $95.5 \%$. For PDW the cut-off was $13.3 \mathrm{fL}$, the area under ROC curve was $0.64(95 \% \mathrm{CI}$ 0.60-0.68), PPV $11.8 \%$ and NPV 95.3\%. The cut-off value for P-LCR was $31.7 \%$, with the area under ROC curve of 0.65 (95\% CI 0.61-0.69), PPV of $11.5 \%$ and NPV of $96 \%$.

According to the index event angiography, in $67 \%(362 / 538)$ patients a single critical lesion was found; $25 \%(135 / 538)$ had 2 -vessel disease and $8 \%(41 / 538)$ suffered from 3 -vessel disease. There were no statistically significant differences between the number of vessels involved and the platelet indices $(\mathrm{p}=0.67$ for MPV, $\mathrm{p}=0.49$ for PDW and $\mathrm{p}=0.63$ for P-LCR).

Platelet volumes and clinical characteristics of subpopulations defined according to cut-off values of platelet parameters.

According to ROC analysis and derived threshold values, high and low risk subsets were identified for 3 platelet parameters. The demographic and clinical data are presented in Table 3. There where no differences in age, gender, concomitant diabetes mellitus, hypertension, history of smoking, hemoglobin concentration nor white blood cell count between the groups. Previous history of MI was related with higher values of PVI, reaching statistical significance of $p=0.031$ and $p=0.043$ for MPV and PDW, respectively. A relationship was also found between PVI and lipid profile, with a statistically significant, positive correlation between P-LCR and serum concentration of high-density cholesterol (HDL) $(\mathrm{p}=0.022)$, as well as low-density cholesterol (LDL) $(\mathrm{p}=0.025)$. MPV correlated with HDL concentration $(\mathrm{p}=0.021)$. The relationship between PDW and HDL and
LDL cholesterol concentration, as well as between MPV and LDL cholesterol concentration did not reach statistical significance, although a positive trend was observed $(\mathrm{p}=0.085, \mathrm{p}=0.107$ and $\mathrm{p}=0.124$, respectively) (Table 4).

\section{Survival analysis}

Mortality rate in the follow-up period was significantly higher in patients with high MPV values than in those with low MPV values (14.6\% [18/123] vs. $5.5 \%$ [23/415], p < 0.001). Similarly, the survival in patients with high PDW was worse than in those with low PDW (mortality $17.4 \%$ [12/69] vs. $6.3 \%$ [28/443], $\mathrm{p}=0.0012$ ). High values of P-LCR were also correlated with higher mortality rate compared to low values of P-LCR (13.8\% [18/130] vs. $5.8 \%$ [22/382], $\mathrm{p}=0.0028$ ). The prevalence of non-fatal reinfarction was insignificantly higher in patients with high PDW (7.2\% vs. $3.2 \%, \mathrm{p}=0.084)$. Repeat coronary revascularization, either percutaneous or surgical, was performed in 5.3\% (29/538) of patients, and the prevalence was higher in patients with high PDW (10.1\% vs. $4.5 \%, \mathrm{p}=0.034)$ and high P-LCR $(8.5 \%$ vs. $4.2 \%, \mathrm{p}=0.041)$. The composite endpoint correlated with MPV $(26.8 \%$ for high MPV values vs. $12.8 \%$ for low MPV, $\mathrm{p}<0.001)$, PDW (34.8\% for high PDW vs. $12.9 \%$ for low PDW, $\mathrm{p}<0001$ ), as well as with P-LCR ( $26.9 \%$ for high values vs. $12 \%$ for low values, $\mathrm{p}=0.0001)$. The results of the survival analysis are shown in Figure 1 and Table 5.

In Cox proportional-hazards regression analysis, abciximab use in clinically evaluated high-risk patients was not found to significantly contribute to the prediction of the unfavourable clinical course and was not included in the model.

\section{Multivariate analysis}

Multivariate analysis was applied to determine the prognostic usefulness of platelet volume parameters as compared with standard clinical variables available during the initial assessment of patients with acute MI. PVI were expressed herein as dichotomous variables (high vs. low).

The univariate analysis showed the following factors to contribute to the prediction of cardiac mortality: age - OR 1.05 (95\% CI 1.02-1.09); MPV - OR 2.92 (95\% CI 1.52-5.61); PDW - OR 3.12 (95\% CI 1.50-6.48); P-LCR - OR 2.63 (95\% CI 1.36-5.08); red blood count - OR 0.50 (95\% CI 0.27-0.93); white blood count - OR 1.14 (95\% CI 1.04-1.25); ejection fraction - OR 0.9614 (95\% CI 0.92-0.99); efficacy of reperfusion expressed by TIMI scale - OR 0.61 (95\% CI $0.44-0.84)$. 
Table 4. Characteristics of subgroups defined by ROC curve analysis.

\begin{tabular}{|c|c|c|c|}
\hline & \multicolumn{2}{|c|}{ Mean platelet volume (MPV) } & \multirow[t]{2}{*}{$\mathbf{P}$} \\
\hline & $M P V<11.7(n=415)$ & $M P V \geq 11.7(n=123)$ & \\
\hline Age [years] & $58 \pm 10$ & $59 \pm 10$ & 0.706 \\
\hline Male & $289(69.6 \%)$ & $83(67.5 \%)$ & 0.650 \\
\hline Diabetes & $48(11.6 \%)$ & $13(10.6 \%)$ & 0.820 \\
\hline Hypertension & $128(30.8 \%)$ & $47(38.2 \%)$ & 0.102 \\
\hline Smoking & $122(29.4 \%)$ & $28(22.8 \%)$ & 0.591 \\
\hline Previous MI & $36(8.7 \%)$ & $19(15.5 \%)$ & 0.031 \\
\hline Total cholesterol [mg/dL] & $208 \pm 48$ & $212 \pm 48$ & 0.389 \\
\hline LDL-cholesterol [mg/dL] & $132 \pm 42$ & $139 \pm 42$ & 0.124 \\
\hline HDL-cholesterol [mg/dL] & $40 \pm 10$ & $43 \pm 13$ & 0.021 \\
\hline Triglycerides [mg/dL] & $162 \pm 104$ & $159 \pm 83$ & 0.790 \\
\hline Hemoglobin [g/L] & $13.6 \pm 2.7$ & $13.4 \pm 2.1$ & 0.316 \\
\hline WBC $\left[\mathrm{n} \times 10^{3} / \mathrm{mm}^{3}\right]$ & $9.9 \pm 3.1$ & $10.2 \pm 3.5$ & 0.346 \\
\hline \multirow[t]{3}{*}{ Platelet count $\left[\mathrm{n} \times 10^{3} / \mathrm{mm}^{3}\right]$} & $238 \pm 69$ & $179 \pm 48$ & $<0.001$ \\
\hline & \multicolumn{2}{|c|}{ Platelet distribution width (PDW) } & $\mathbf{P}$ \\
\hline & PDW $<16(n=443)$ & $P D W \geq 16(n=69)$ & \\
\hline Age [years] & $58 \pm 10$ & $60 \pm 9$ & 0.185 \\
\hline Male & $309(69.7 \%)$ & $47(68.1 \%)$ & 0.784 \\
\hline Diabetes & $46(9.8 \%)$ & $8(11.3 \%)$ & 0.759 \\
\hline Hypertension & $143(30.6 \%)$ & $23(32.4 \%)$ & 0.887 \\
\hline Smoking & $123(26.3 \%)$ & $16(22.5 \%)$ & 0.417 \\
\hline Previous MI & $38(8.1 \%)$ & $12(16.9 \%)$ & 0.043 \\
\hline Total cholesterol [mg/dL] & $206 \pm 47$ & $209 \pm 43$ & 0.659 \\
\hline LDL-cholesterol [mg/dL] & $130 \pm 42$ & $140 \pm 35$ & 0.107 \\
\hline HDL-cholesterol [mg/dL] & $40 \pm 10$ & $43 \pm 13$ & 0.085 \\
\hline Triglycerides [mg/dL] & $163 \pm 104$ & $156 \pm 82$ & 0.535 \\
\hline Hemoglobin $[\mathrm{g} / \mathrm{dL}]$ & $13.6 \pm 1.8$ & $13.2 \pm 1.6$ & 0.090 \\
\hline WBC $\left[\mathrm{n} \times 10^{3} / \mathrm{mm}^{3}\right]$ & $10 \pm 3.2$ & $9.6 \pm 3.4$ & 0.370 \\
\hline \multirow[t]{3}{*}{ Platelet count $\left[\mathrm{n} \times 10^{3} / \mathrm{mm}^{3}\right]$} & $234 \pm 69$ & $168 \pm 50$ & $<0.001$ \\
\hline & \multicolumn{2}{|c|}{ Platelet large cell ratio (P-LCR) } & $\mathbf{P}$ \\
\hline & P-LCR $<38.1(n=383)$ & P-LCR $\geq 38.1$ (n = 129) & \\
\hline Age [years] & $58 \pm 10$ & $59 \pm 10$ & 0.524 \\
\hline Male & $269(70 \%)$ & $87(67.4 \%)$ & 0.552 \\
\hline Diabetes & $40(10.5 \%)$ & $14(10.8 \%)$ & 0.318 \\
\hline Hypertension & $117(30.6 \%)$ & $49(38 \%)$ & 0.467 \\
\hline Smoking & $103(27 \%)$ & $36(27.9 \%)$ & 0.762 \\
\hline Previous MI & $32(8.4 \%)$ & $19(14.7 \%)$ & 0.064 \\
\hline Total cholesterol [mg/dL] & $204 \pm 46$ & $214 \pm 48$ & 0.070 \\
\hline LDL-cholesterol [mg/dL] & $129 \pm 41$ & $140 \pm 41$ & 0.025 \\
\hline HDL-cholesterol [mg/dL] & $40 \pm 10$ & $43 \pm 13$ & 0.022 \\
\hline Triglycerides [mg/dL] & $163 \pm 107$ & $157 \pm 82$ & 0.590 \\
\hline Haemoglobin [g/dL] & $13.6 \pm 1.6$ & $13.5 \pm 2$ & 0.398 \\
\hline WBC $\left[\mathrm{n} \times 10^{3} / \mathrm{mm}^{3}\right]$ & $9.9 \pm 3.1$ & $10.2 \pm 3.4$ & 0.482 \\
\hline Platelet count $\left[\mathrm{n} \times 10^{3} / \mathrm{mm}^{3}\right]$ & $239 \pm 71$ & $181 \pm 47$ & $<0.001$ \\
\hline
\end{tabular}

$\mathrm{MI}$ - myocardial infarction; WBC — white blood count 


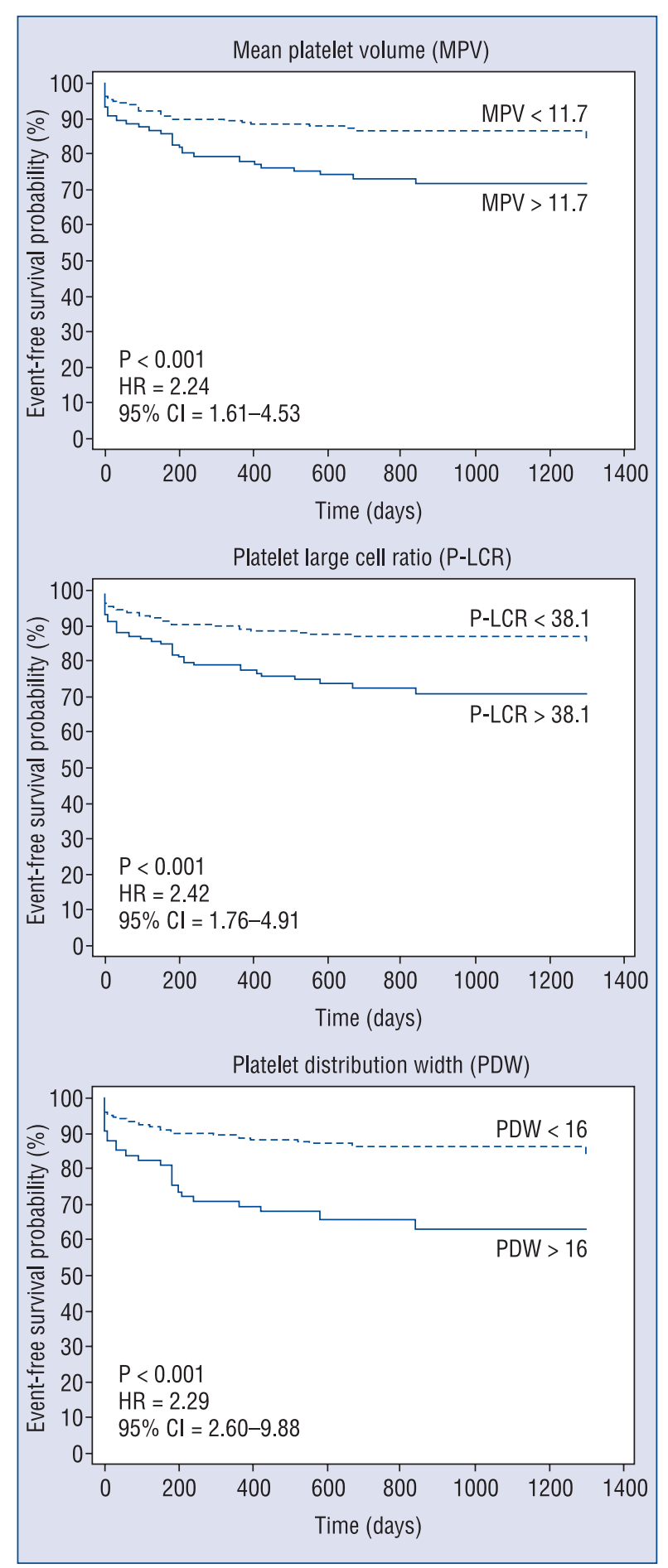

Figure 1. Platelet volume indices and event-free survival in 2-year follow-up: Kaplan-Meier survival curves; $\mathrm{HR}$ - hazard ratio; $95 \% \mathrm{Cl}-95 \%$ confidence interval; $\mathrm{p}$ - statistical significance.

In the multivariate analysis age, PDW, red blood count, white blood count and efficacy of reperfusion were found to be independent prognostic factors of cardiac mortality in a 2-year follow up $(\mathrm{p}<0.001)$ (Table 6).

No variables were shown to be independent prognostic factors for reinfarction, nor for the need of another revascularization procedure.

For the prediction of occurrence of the composite endpoint, age — OR 1.03 (95\% CI 1.01-1.06); MPV - OR 2.50 (95\% CI 1.53-4.10); PDW - OR 3.61 (95\% CI 2.05-6.37); P-LCR - OR 2.69 (95\% CI 1.64-4.41) and efficacy of reperfusion - OR 0.72 (95\% CI 0.54-0.96) were proved significant in the univariate analysis. In the multivariate logistic regression, only age, PDW and efficacy of reperfusion were found to independently predict the occurrence of cardiac death, reinfarction or need for another revascularization procedure $(\mathrm{p}<0.001)$ (Table 7).

\section{Discussion}

The main findings of our study indicate that platelet parameters, easily available from automated cell counters, are powerful predictors of unfavourable clinical course in patients with MI treated with primary percutaneous intervention. For the first time, PDW and P-LCR were identified as prognostic predictors after MI. Importantly, their prognostic value was stronger than that previously reported of MPV. Additional prediction of reinfarction and repeat revascularization using PDW became thus feasible.

\section{Baseline platelet volume indices}

In the present study, the groups seem to be well balanced in terms of most of the conventional risk factors of acute coronary events [12]. However, larger platelets are detected in patients with higher values of LDL and HDL cholesterol. This is consistent with some previous findings [13], although other studies did not prove such correlation $[5,7]$. In the present study, PVI are also raised in a small $(10.2 \%)$ subset of patients with past history of MI compared to those with the first episode of an acute coronary event; in the literature there is also evidence of protracted circulation of larger platelets after acute MI $[6,7,13]$. The presence of larger platelet size in patients with history of the coronary artery disease may be interpreted as a consequence of platelet consumption at the site of coronary lesion and subsequent stimulation of the bone marrow [2]. Platelets produced under conditions of stimulated thrombocytopoiesis, called "stress" platelets by Tong at al. [14], tend to show increased MPV. Similarly, there is strong evidence 
Table 5. The relationship of platelet parameters with post-infarction clinical course: Kaplan-Meier survival analysis.

\begin{tabular}{lccc}
\hline & $\begin{array}{c}\text { Mean platelet } \\
\text { volume }\end{array}$ & $\begin{array}{c}\text { Platelet distribution } \\
\text { width }\end{array}$ & $\begin{array}{c}\text { Platelet large } \\
\text { cell ratio }\end{array}$ \\
\hline Cardiac death & $\mathrm{p}<0.001$ & $\mathrm{p}=0.0012$ & $\mathrm{p}=0.0025$ \\
& $\mathrm{HR}=2.73$ & $\mathrm{HR}=2.88$ & 2.51 \\
Reinfarction & $95 \% \mathrm{Cl}=1.70-7.50$ & $95 \% \mathrm{Cl}=1.84-11.80$ & $95 \% \mathrm{Cl}=1.48-6.33$ \\
& $\mathrm{p}=0.42$ (NS) & $\mathrm{p}=0.084$ & $\mathrm{p}=0.42$ (NS) \\
& $\mathrm{HR}=1.47$ & $\mathrm{HR}=2.39$ & $\mathrm{HR}=1.48$ \\
Revascularization & $95 \% \mathrm{Cl}=0.54-4.37$ & $95 \% \mathrm{Cl}=0.85-12.38$ & $95 \% \mathrm{Cl}=0.53-4.43$ \\
& $\mathrm{p}=0.218(\mathrm{NS})$ & $\mathrm{p}=0.034$ & $\mathrm{p}=0.041$ \\
Composite endpoint & $\mathrm{HR}=1.63$ & $\mathrm{HR}=2.46$ & $\mathrm{HR}=2.18$ \\
Death + reinfarction & $95 \% \mathrm{Cl}=0.72-4.24$ & $95 \% \mathrm{Cl}=1.10-10.90$ & $95 \% \mathrm{Cl}=1.04-6.12$ \\
+ revascularization) & $\mathrm{p}<0.001$ & $\mathrm{p}<0.001$ & $\mathrm{p}<0.001$ \\
\hline
\end{tabular}

$\mathrm{Cl}$ - confidence interval; $\mathrm{HR}$ - hazard ratio; NS - non-significant; $\mathrm{p}$ - statistical significance

Table 6. Impact of variables significant in the univariate analysis on the prediction of cardiac mortality: multivariate logistic regression.

\begin{tabular}{lcccc}
\hline Factor & RC & OR & $95 \%$ Cl & P \\
\hline Platelet distribution width $[\mathrm{fL}]$ & 1.08 & 2.96 & $1.23-7.09$ & 0.015 \\
White blood count $\left[\mathrm{n} \times 10^{3}\right]$ & 0.13 & 1.13 & $1.03-1.26$ & 0.015 \\
Age [years] & 0.04 & 1.04 & $1.00-1.09$ & 0.013 \\
Efficacy of reperfusion & -0.49 & 0.61 & $0.41-0.90$ & 0.013 \\
Red blood count $\left[\mathrm{n} \times 10^{6}\right]$ & -0.67 & 0.51 & $0.27-0.98$ & 0.044 \\
\hline
\end{tabular}

$\mathrm{RC}$ - regression coefficient; $\mathrm{OR}$ - odds ratio; $95 \% \mathrm{Cl}-95 \%$ confidence interval; $\mathrm{p}$ - statistical significance; efficacy of reperfusion assessed with TIMI scale 0-3

Table 7. Impact of variables significant in the univariate analysis on the prediction of the composite endpoint: multivariate logistic regression.

\begin{tabular}{lcccc}
\hline Factor & RC & OR & 95\% Cl & P \\
\hline Platelet distribution width [fL] & 1.15 & 3.15 & $1.74-5.70$ & $<0.001$ \\
Age [years] & 0.03 & 1.04 & $1.01-1.06$ & 0.020 \\
Efficacy of reperfusion & -0.38 & 0.69 & $0.51-0.93$ & 0.014 \\
\hline
\end{tabular}

$\mathrm{RC}$ - regression coefficient; OR - odds ratio; $95 \% \mathrm{Cl}$ - 95\% confidence interval; $\mathrm{p}$ - statistical significance; efficacy of reperfusion assessed with TIMI scale $0-3$

of an increase in platelet size after CABG, following the destruction of platelets in the extracorporeal circulation [15]. In accordance with previous reports, in the present study a strong negative correlation between platelet count and size was noticed [9].

\section{Clinical outcomes}

Platelet on-treatment hyperreactivity, measured by aggregation following agonists stimulation, has been proved to influence the prognosis in patients after PCI [16].
Although postinfarction antiplatelet treatment was uniform, no information is available on patients' previous use of antiplatelet drugs. No literature data, however, suggest any impact of antiplatelet drugs on platelet volume [17].

Moreover, the analysis of the impact of other compounds was not included in this study, with special emphasis on insulin as opposed to oral hypoglycemic treatment in diabetic patients, though it should be stated that the correlation of platelet volume and insulin dependence was denied by 
some authors [18]. Recently, Jindal et al. [19] reported that diabetics in general, and diabetics with microvascular complications in particular have higher values of PDW, in our study we did not observed any difference between prevalence of diabetes mellitus between patients divided according to cut-off PDW value. Lack of inclusion of any data on beta-blockers or statins intake as known predictors of mortality beyond hospital phase - makes the results of multivariate analysis not as informative as possible [20]. EDTA is recognized to provide the best conditions of anticoagulation for both routine clinical and research laboratory measurement of platelet volume [21, 22]. However, previous studies reported platelet swelling when EDTA was used as an anticoagulant. It was also implied that the swelling may be associated with different EDTA amounts in the tubes [3]. To minimize the effect, all measurements were performed within $1 \mathrm{~h}$ from blood collection, since according to recent findings, the increase in MPV can be diminished up to approximately $<0.5 \mathrm{fL}$, as long as the analysis is performed within $2 \mathrm{~h}$ after venipuncture [6].

The study protocol included single time PVI measurement. In the setting of acute ST elevation MI patients one cannot exclude influence of confounding factors on platelet function parameters. PVI were not re-evaluated on discharge, which might have been useful to better define their prognostic implications.

Furthermore, the measurement of PVI can only indirectly extrapolate the presence of circulating larger platelets, while direct measurement, available with more advanced techniques like flow cytometry, might be a more sensitive marker in determining high-risk patients in relation to the hyperactivity that large platelets show despite the treatment with antiplatelet agents [23].

\section{Conclusions}

Our findings indicate that not only MPV, but also other PVI, namely PDW and P-LCR, can serve as useful prognostic factors for long-term mortality in patients after acute MI. PDW was found to be one of independent risk factors of cardiac mortality, as well as of the occurrence of either death, recurrent MI or need for another revascularization procedure. Thus, in the management of the acute phase of coronary events, PVI may become a valuable contribution to identification of high-risk patients, who might require more potent antiplatelet therapy.

Conflict of interest: none declared

\section{References}

1. Thompson CB, Jakubowski JA, Quinn PG, Deykin D, Valeri CR. Platelet size as a determinant of platelet function. J Lab Clin Med, 1983; 101: 205-213.

2. Isik T, Ayhan E, Uyarel $\mathrm{H}$ et al. Increased mean platelet volume associated with extent of slow coronary flow. Cardiol J, 2012; 19: 355-362.

3. Pizzuli L, Yang A, Martin JF, Luderitz B. Changes in platelet size and count in unstable angina compared to stable angina and non-cardiac chest pain. Eur Heart J, 1998; 19: 80-84.

4. Greisenegger S, Endler G, Hsieh K, Tentschert S, Mannhalter C, Lalouschek W. Is elevated mean platelet volume associated with a worse outcome in patients with acute ischaemic cerebrovascular events? Stroke, 2004; 35: 1688-1691.

5. Bath P, Algert C, Chapman N, Neal B. Association of mean platelet volume with risk of stroke among 3134 individuals with history of cerebrovascular disease. Stroke, 2004; 35: 622-626.

6. Kilicki-Camur N, Demirtunc R, Konuralp C, Eskiser A, Basaran Y. Could mean platelet volume be a predictive marker for acute myocardial infarction? Med Sci Monit, 2005; 11: 387-392.

7. Endler G, Klimesch A, Sunder-Plassmann H et al. Mean platelet volume is an independent risk factor for myocardial infarction but not for coronary artery disease. Br J Haemat, 2002; 117: 399-404.

8. Tekbas E, Kara AF, Ariturk $Z$ et al. Mean platelet volume in predicting short- and long-term morbidity and mortality in patients with or without ST-segment elevation myocardial infarction. Scand J Clin Lab Invest, 2011; 71: 613-619.

9. Huczek Z, Kochman J, Filipiak K et al. Mean platelet volume on admission predicts impaired reperfusion and long-term mortality in acute myocardial infarction treated with primary percutaneous coronary intervention. J Am Coll Cardiol, 2005; 46: 284-290.

10. Huczek Z, Filipiak JK, Kochman J et al. Baseline platelet size is increased in patients with acute coronary syndromes developing early stent thrombosis and predicts future residual platelet reactivity. A case-control study. Thrombosis Res, 2010; 125: 406-412.

11. Thygesen K, Alpert JS, White HD; Joint ESC/ACCF/AHA/WHF Task Force for the Redefinition of Myocardial Infarction. Universal definition of myocardial infarction. Eur Heart J, 2007; 28: 2525-2538.

12. Jankowska B, Uchmanowicz I, Łoboz-Grudzień K, Dudek K. Prevalence of risk factors in patients with acute coronary syndrome (ACS): sex related differences. Pol Przegl Kardiol, 2010; 12: 287-290.

13. Grotto HZ, Noronha JF. Platelet large cell ratio (P-LCR) in patients with dyslipidemia. Clin Lab Haem, 2004; 26: 347-349.

14. Tong M, Seth P, Penington DG. Proplatelets and stress platelets. Blood, 1987; 69: 522-528.

15. Martin JF, Daniels TD, Trowbridge EA. Acute and chronic changes in platelet volume and count after cardiopulmonary bypass-induced thrombocytopenia in man. Thromb Haemost, 1987; 57: 55-58.

16. Marucci R, Gori AM, Paniccia R et al. High on-treatment platelet reactivity by more than one agonist predicts 12 -month follow-up cardiovascular death and non-fatal myocardial infarction in acute coronary syndrome patients receiving coronary stenting. Thrombosis and Heamostasis, 2010: 104: 279-286.

17. Thompson CB, Love DG, Quinn PG, Valeri CR. Platelet size does not correlate with platelet age. Blood, 1983; 62: 487-494.

18. Papanas N, Symeonidis G, Maltezos E et al. Mean platelet volume in patients with type 2 diabetes mellitus. Platelets, 2004; 15: 475-478.

19. Jindal S, Gupta S, Gupta R et al. Platelet indices in diabetes mellitus: indicators of diabetic microvascular complications. Hematology, 2011; 16: 86-89.

20. Postula M, Rosiak M, Kaplon-Cieslicka A et al. Do statins influence platelet reactivity on acetylsalicylic acid therapy in patients with type 2 diabetes? Cardiol J, 2012; 19: 494-500.

21. Thompson CB, Diaz DD, Quinn PG, Lapins M, Kurtz SR, Valeri CR. The role of anticoagulation in the measurement of platelet volumes. Am J Clin Pathol, 1983; 80: 327-332.

22. Khandekar MM, Khurana AS, Deshmukh SD, Kakrani AL, Katdare AD, Inamdar AK. Platelet volume indices in patients with coronary artery disease and acute myocardial infarction: an Indian scenario. J Clin Pathol, 2006; 59: 146-149.

23. Guthikonda S, Lev EI, Patel R et al. Reticulated platelets and uninhibited COX-1 and COX-2 decrease the antiplatelet effects of aspirin. J Thromb Haemost, 2007; 5: 490-496. 